\title{
ESTUDO DA ADSORÇÃO DO ÁCIDO LÁTICO POR CROMATOGRAFIA DE TROCA IÔNICA
}

\author{
M. R. A. ARCANJO ${ }^{1}$; F. A. N. FERNANDES ${ }^{1}$; I. J. SILVA Jr ${ }^{1}$ \\ ${ }^{1}$ Universidade Federal do Ceará, Departamento de Engenharia Química \\ E-mail para contato: rosienearcanjo@gmail.com
}

\begin{abstract}
RESUMO: O ácido lático existe como dois isômeros ópticos, $\mathrm{D}$ e L-ácido lático, podendo ser produzido por síntese química ou por fermentação. Esse ácido orgânico tem sido amplamente utilizado nas indústrias alimentícias, farmacêuticas, cosméticas e químicas. Recentemente, há um interesse contínuo em um processo mais eficiente para a sua recuperação e purificação. O objetivo do presente trabalho foi realizar um estudo sobre a adsorção de ácido lático (oriundo da conversão do glicerol resultante da produção do biodiesel) em resinas visando sua purificação por cromatografia de troca iônica. Os estudos foram realizados com duas resinas de troca iônica, Amberlite IRA 67 e IRA96. Foram estudadas as isotermas de adsorção em diferentes concentrações de alimentação de ácido lático (60-302 g/L) nas temperaturas de $30^{\circ} \mathrm{C}, 40^{\circ} \mathrm{C}$ e $60^{\circ} \mathrm{C}$ e a avaliação da adsorção/dessorção de soluções monocomponentes, binárias e mistura real. Os resultados experimentais se ajustaram com boa aproximação ao modelo de Langmuir, obtendo-se uma adsorção máxima de 544 g/L e 341 g/L para Amberlite IRA 96 e IRA 67, respectivamente. As resinas utilizadas mostraram melhores resultados na temperatura de $30^{\circ} \mathrm{C}$, sendo a Amberlite IRA 96, o adsorvente que apresentou melhor eficiência na adsorção de ácido lático.
\end{abstract}

\section{INTRODUÇÃO}

O ácido lático é um ácido orgânico que existe como dois isômeros ópticos, D e L-ácido lático (Hofvendahl e Hahn-Hägerdal, 2000). O ácido lático tem sido extensivamente utilizado em diversas aplicações industriais (Dey e Pal, 2012). O ácido lático pode ser produzido por síntese química ou por processo fermentativo (Abdel-Rahman et al., 2011). Estudos recentes avaliam a produção de ácido lático através da conversão hidrotérmica da glicerina resultante da produção do biodiesel (Shen et al., 2009), como uma alternativa de agregar valor para a produtividade da indústria de biodiesel (Lopes et al., 2011), visto que um volume excedente de glicerina é gerado ultrapassando a demanda e a capacidade de absorção dos mercados atuais (Umpierre e Machado, 2013).

Há um interesse contínuo em um processo mais eficiente para a produção de ácido lático, assim como para a sua recuperação e purificação (Wasewar, 2005). Diversos estudos têm sido relatados na literatura para a recuperação de ácido lático, contudo, a adsorção por troca iônica vem ganhando destaque por se mostrar uma técnica atrativa e economicamente viável para a recuperação e purificação de bioprodutos (Silva, 2010).

Nesse contexto, o presente estudo teve como objetivo avaliar a aplicação da adsorção do ácido lático por troca iônica utilizando fases estacionárias (resinas Amberlite IRA 67 e IRA 96) 
visando a recuperação do ácido lático oriundo da conversão do glicerol resultante da produção do biodiesel.

\section{MATERIAIS E MÉTODOS}

\subsection{Materiais}

Reagentes: ácido lático $85 \%\left(\mathrm{C}_{3} \mathrm{H}_{6} \mathrm{O}_{3}\right)$ utilizado nas soluções sintéticas para obtenção das isotermas de adsorção monocomponentes e misturas binárias foi proveniente da Vetec (Brasil). Todos os outros reagentes utilizados foram de grau analítico da Vetec (Brasil).

Resinas de troca iônica: Amberlite IRA 67 e IRA 96 (resinas de troca aniônica fraca) (Rohm \& Haas, Brasil). A Tabela 1 apresenta o tipo de resina testada, segundo suas características.

Tabela 1 - Características das resinas testadas (Dados fornecidos pelo fabricante)

\begin{tabular}{ccccccc}
\hline Adsorvente & Tipo & $\begin{array}{c}\text { Forma } \\
\text { física }\end{array}$ & $\begin{array}{c}\text { Grupo } \\
\text { Funcional }\end{array}$ & Matriz & $\begin{array}{c}\text { Tamanho } \\
\text { de partícula } \\
\text { (mm) }\end{array}$ & $\begin{array}{c}\text { Concentração } \\
\text { de sítios } \\
\text { ativos (eq/L) }\end{array}$ \\
\hline $\begin{array}{c}\text { Amberlite } \\
\text { IRA 67 }\end{array}$ & $\begin{array}{c}\text { Aniônica } \\
\text { fraca }\end{array}$ & $\begin{array}{c}\text { Esféricas, } \\
\text { brancas e } \\
\text { translúcidas }\end{array}$ & Poliamina & $\begin{array}{c}\text { Gel Acrílico } \\
\text { Reticulado }\end{array}$ & $0,50-0,75$ & $\geq 1,60$ \\
Amberlite & Aniônica & Esféricas e \\
IRA 96 & fraca & Poliamina & $\begin{array}{c}\text { Macroreticular } \\
\text { de Estireno- } \\
\text { divinilbenzeno }\end{array}$ & $0,0,55-0,75$ & $\geq 1,25$ \\
& & & & & & \\
\hline
\end{tabular}

Coluna cromatográfica: A coluna cromatográfica da Superfomance (Gotec Labortechnic) para experimentos em leito fixo foi empacotada com a Amberlite IRA 67 (Sigma-Aldrich), nas dimensões 2,5 cm x $11 \mathrm{~cm}$ e Amberlite IRA 96 (Sigma-Aldrich), nas dimensões 2,5 cm x 11,3 $\mathrm{cm}$.

\subsection{Procedimento Experimental}

Determinação de isotermas de adsorção monocomponentes em leito fixo: Lavou-se a coluna com água deionizada, a uma vazão de $2,5 \mathrm{~mL} / \mathrm{min}$ por um determinado período, para garantir que todo o sistema estivesse equilibrado; Em seguida, no instante convencionado como $\mathrm{t}=0$, passou-se a bombear uma solução de ácido lático à mesma vazão através da coluna por tempo suficiente para saturá-la completamente. Durante esta etapa de saturação recolheram-se frações de aproximadamente $5,0 \mathrm{~mL}$ em pequenos recipientes à saída da coluna, as quais foram analisadas pelo método de titulação com $\mathrm{NaOH} 6 \mathrm{M}$ a fim de se obter a concentração do ácido no equilíbrio. $\mathrm{O}$ indicador utilizado foi fenolftaleína $1 \%$. Após a saturação da coluna, foi feita a lavagem (água Milli-Q), eluição $(\mathrm{HCl} 1,0 \mathrm{M})$, regeneração $(\mathrm{NaOH} 0,5 \mathrm{M})$ e novamente lavagem (água Milli-Q) da mesma. Este procedimento foi repetido sucessivas vezes para diferentes concentrações de alimentação com soluções monocomponentes de ácido lático nas concentrações $\left(\mathrm{C}_{0}\right)$ de 60 a $302 \mathrm{~g} / \mathrm{L}$ em três temperaturas $\left(30^{\circ} \mathrm{C}, 40^{\circ} \mathrm{C}\right.$ e $\left.60^{\circ} \mathrm{C}\right)$. As curvas de breakthrough foram obtidas, e a partir delas, foi possível realizar a estimativa de parâmetros cinéticos. A partir dos dados de concentração de ácido lático, para cada condição estudada, fez- 
se o ajuste do modelo da isoterma de adsorção de Langmuir (Equação 1) pelo software ORIGIN 6.0 (Microcal Software).

$$
q^{*}=\frac{H C_{e q}}{1+b C_{e q}}
$$

em que $H$ e $b(\mathrm{~L} / \mathrm{g})$ são parâmetros do modelo de Langmuir, sendo a capacidade máxima da monocamada dada por $b . q m=H$ e $b$ é a constante de Langmuir e $C_{e q}$ é a concentração do adsorbato na solução após atingir o equilíbrio.

Ensaios de adsorção e dessorção monocomponentes/ mistura binária/ mistura real em leito fixo: Depois de concluída a estabilização com a passagem contínua de água Milli-Q, começou-se a bombear a solução de ácido lático sintética numa concentração inicial conhecida em sentido ascendente. Após a saturação da coluna, esta foi lavada com água Milli-Q e a eluição foi realizada com uma solução de $\mathrm{HCl}$ 1,0M. Amostras foram coletadas, em volumes prédeterminados e em intervalos de 4 minutos, sendo as concentrações de ácido lático determinadas por GC-FID (Thermos modelo Ultra). O mesmo procedimento foi realizado com a mistura binária (ácido lático + glicerol) e mistura real advinda do processo químico.

Vale ressaltar que outros compostos não foram identificados nesse experimento, pois na conversão química do glicerol excedente do biodiesel além de ácido lático, reações secundárias são responsáveis pela produção de ácido acético e ácido fórmico, porém em quantidades bem pequenas, uma vez que a seletividade da reação é maior para a produção de ácido lático.

\section{RESULTADOS E DISCUSSÃO}

\subsection{Determinação de Isotermas Monocomponentes em Leito fixo}

Conforme é apresentado na Figura 1 (a e b), podemos observar as curvas de ruptura do ácido lático na resina Amberlite IRA 67 e IRA 96, respectivamente, para uma concentração de alimentação igual a $302 \mathrm{~g} / \mathrm{L}$ nas três temperaturas estudadas. Cada curva de ruptura apresentada mostra a variação da concentração de adsorbato com o tempo à saída da coluna, permitindo calcular um ponto na isoterma de adsorção $\left(q^{*}, C_{0}\right)$. Da observação das curvas de ruptura apresentadas pode-se ter uma ideia do comportamento de remoção do ácido lático pela resina, na operação em coluna de leito fixo. É possível a identificação de regiões do comportamento que vão desde o início da saturação da resina (ponto de ruptura onde $\mathrm{C}(\mathrm{t}) / \mathrm{C}_{0}=0,10$ ), na qual se inicia a elevação brusca da curva, até a saturação total da resina, quando $\mathrm{C}(\mathrm{t}) / \mathrm{C}_{0}=1$, ou seja, quando a concentração de saída da coluna é igual à concentração da solução de alimentação. Deste modo, podem ser estimados das curvas de ruptura não só o tempo de operação da coluna até saturação total, como a quantidade de ácido removido pela resina durante a operação assim como, outras informações do processo em coluna.

Nota-se nas curvas da Figura 1 ( a e b), que o tempo necessário para o sistema atingir o equilíbrio, ou seja, a completa saturação foi ligeiramente menor para a resina Amberlite IRA 67 do que para a Amberlite IRA 96. A alta capacidade de adsorção mostrada pela Amberlite IRA 96, em comparação com Amberlite IRA 67 foi explicado pela maior porosidade da Amberlite IRA 96 (uma resina macroporosa com alta porosidade) que permitiu um acesso mais fácil das espécies químicas para a superfície interior da resina (Alonso e Parajó, 2001). 


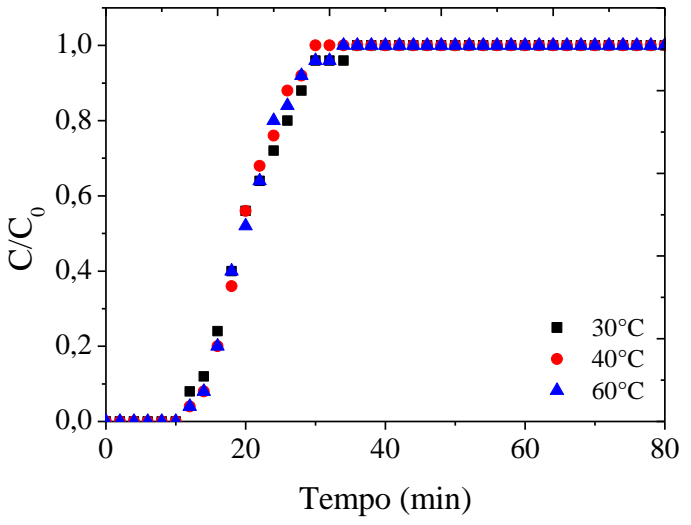

(a)

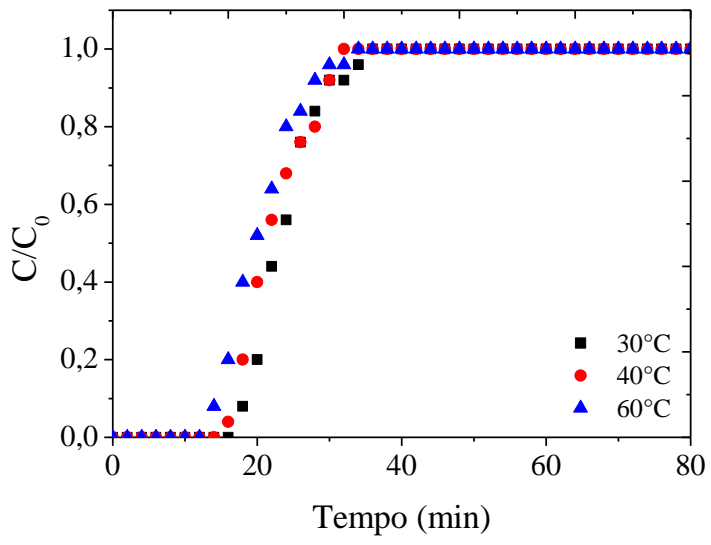

(b)

Figura 1 - Curvas de breakthrough (experimentais) para o ácido lático com concentração de alimentação de 302 g/L na resina Amberlite IRA 67 (a) e na Amberlite IRA 96 (b).

A partir dos dados de concentração de ácido lático, para cada condição estudada, alguns modelos de isotermas de adsorção foram estudados, destacando-se o modelo de Langmuir, no qual os pontos experimentais se ajustaram com melhor aproximação (Figura $2 \mathrm{a}$ e b). Para tal foi empregado o software ORIGIN 6.0 (Microcal Software). Foram utilizados para cada ajuste no mínimo 5 pontos experimentais, a fim de se determinar os dois parâmetros do modelo $(b$ e $q_{m}$ ). Estes parâmetros caracterizam o sistema em termos da preferência de adsorção na resina e capacidade máxima de adsorção, sendo possível a partir destes avaliar as diferentes condições estudadas.

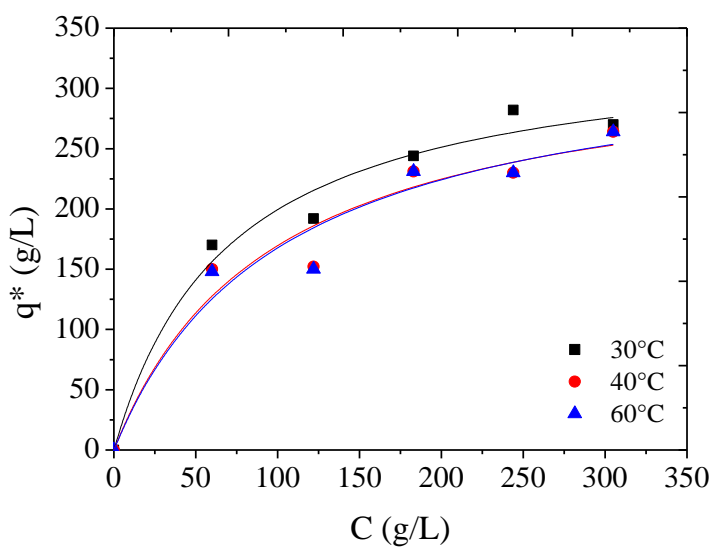

(a)

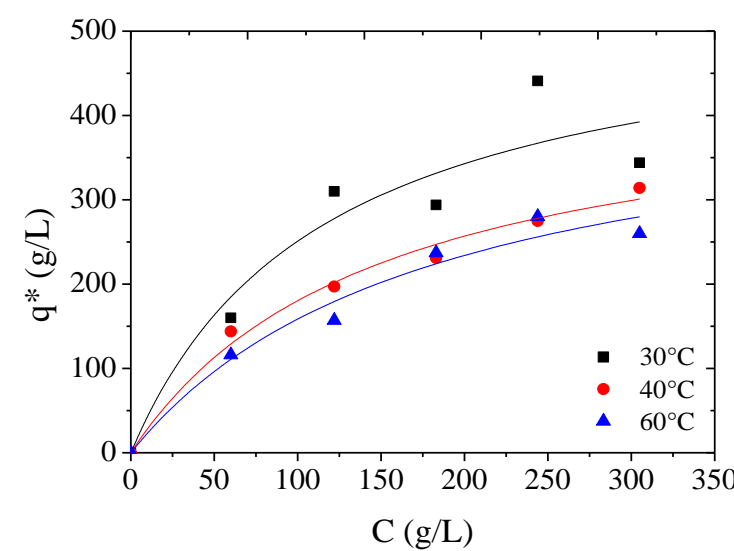

(b)

Figura 2 - Isotermas de adsorção de ácido lático a várias concentrações (60, 120, 180, 240, 302 g/L) na resina Amberlite IRA 67 (a) e Amberlite IRA 96 (b). As curvas representam os dados experimentais ajustados ao modelo de Langmuir.

De acordo com a Figura 2 (a e b) apresentada, vimos que a capacidade de adsorção do ácido lático nas resinas utilizadas diminui ligeiramente com o aumento de temperatura, sendo a adsorção um processo exotérmico, apesar da pouca diferença, a melhor temperatura avaliada foi de $30^{\circ} \mathrm{C}$. Os ajustes não lineares das isotermas de adsorção obtidos pelo software citado anteriormente e os parâmetros do modelo são apresentados na Tabela 2. 
Tabela 2 - Constantes de Langmuir $q_{m}$ e $b$, a várias temperaturas nas Resinas Amberlite IRA 67 e IRA 96

\begin{tabular}{ccccc}
\hline Adsorventes & Parâmetros & \multicolumn{3}{c}{ Temperatura } \\
\cline { 2 - 4 } & & $\mathbf{3 0}^{\circ} \mathbf{C}$ & $\mathbf{4 0}^{\circ} \mathbf{C}$ & $\mathbf{6 0}^{\circ} \mathbf{C}$ \\
\hline \multirow{3}{*}{ Amberlite } & $q_{m}(\mathrm{~g} / \mathrm{L})$ & $341 \pm 1,06$ & $340 \pm 1,03$ & $340 \pm 0,99$ \\
\cline { 2 - 5 } IRA 67 & $b(\mathrm{~L} / \mathrm{g})$ & $0,014 \pm 0,005$ & $0,01 \pm 0,004$ & $0,009 \pm 0,004$ \\
\cline { 2 - 4 } & $\chi^{2}$ & 0,0001 & 0,0005 & 0,0005 \\
\cline { 2 - 5 } & $\mathrm{R}^{2}$ & 0,9802 & 0,9573 & 0,9564 \\
\hline \multirow{3}{*}{ Amberlite } & $q_{m}(\mathrm{~g} / \mathrm{L})$ & $544 \pm 2,06$ & $450 \pm 0,40$ & $450 \pm 0,55$ \\
\cline { 2 - 5 } IRA 96 & $b(\mathrm{~L} / \mathrm{g})$ & $0,008 \pm 0,003$ & $0,006 \pm 0,004$ & $0,005 \pm 0,003$ \\
\cline { 2 - 5 } & $\chi^{2}$ & 0,0027 & 0,0002 & 0,0004 \\
\cline { 2 - 5 } & $\mathrm{R}^{2}$ & 0,9094 & 0,9896 & 0,9707 \\
\hline
\end{tabular}

\subsection{Ensaios de adsorção e dessorção monocomponentes em leito fixo}

A Figura 3 ( $a$ e b) mostram os cromatogramas obtidos para a solução comercial de ácido lático (a uma concentração de 120 g/L) na resina Amberlite IRA 67 e a Amberlite IRA 96, respectivamente.

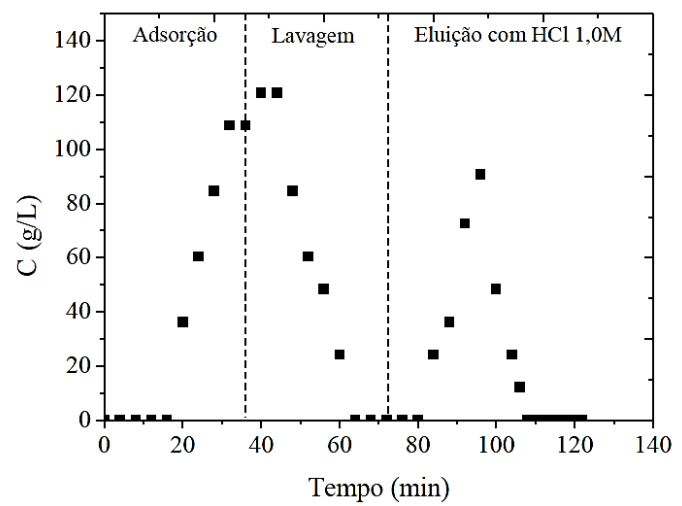

(a)

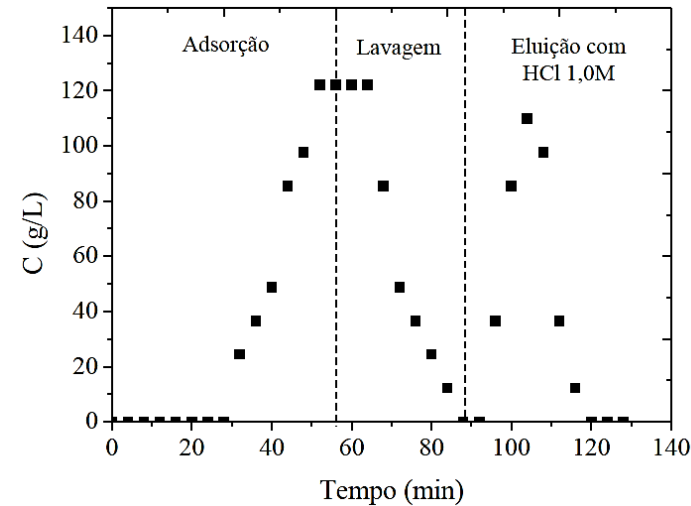

(b)

Figura 3 - (a) Cromatograma para solução de ácido lático a uma concentração de entrada de $\mathrm{C}_{0 \text { Ácido lático }}$ $=120 \mathrm{~g} / \mathrm{L}(\mathbf{\bullet}) ; \mathrm{T}=30^{\circ} \mathrm{C} ; \mathrm{Q}=2,5 \mathrm{~mL} / \mathrm{min}$ na resina Amberlite IRA 67 (a) e Amberlite IRA 96 (b).

Pode se observar na tabela 3, que o percentual de recuperação do ácido lático comercial da solução na etapa de eluição, foi de 25,83\% (31 g/L) para a resina Amberlite IRA 67 e de 29,17\% (35 g/L) para a resina Amberlite IRA 96. Vale ressaltar que pode ter havido eventuais perdas (mínimas) de amostras durante o processo. Para ambas as resinas, a separação do ácido lático também foi avaliada em termos de produtividade (onde $P R=C$ (concentração na etapa de eluição). $Q$ (vazão) $/ M_{\text {ads }}$ (massa do adsorvente)). Foram obtidos valores de 2,78 e $3,15 \mathrm{Kg}$ de ácido lático/kg de resina.dia para a resina Amberlite IRA 67 e IRA 96, respectivamente. 
Tabela 3 - Etapas da corrida cromatográfica da solução monocomponente de ácido lático na resina Amberlite IRA 67 e IRA 96

\begin{tabular}{|c|c|c|c|c|c|c|}
\hline \multirow[b]{2}{*}{ Etapa } & \multicolumn{3}{|c|}{ Amberlite IRA 67} & \multicolumn{3}{|c|}{ Amberlite IRA 96} \\
\hline & $\begin{array}{c}\text { Conc. } \\
(\mathrm{g} / \mathrm{L})\end{array}$ & $\begin{array}{l}\text { Percentual da } \\
\text { conc. }(\%)\end{array}$ & $\begin{array}{c}\text { PR } \\
\text { (kg/ (kg. dia) }\end{array}$ & $\begin{array}{l}\text { Conc. } \\
(\mathrm{g} / \mathrm{L})\end{array}$ & $\begin{array}{c}\text { Percentual da } \\
\text { conc. }(\%)\end{array}$ & $\begin{array}{c}\text { PR } \\
\text { (kg/ (kg. dia) }\end{array}$ \\
\hline Alimentação & 120 & 100 & & 120 & 100 & \\
\hline Adsorção & 52 & 43,33 & 2,78 & 41 & 34,17 & 3,15 \\
\hline Lavagem & 34 & 28,33 & & 43 & 35,83 & \\
\hline Eluição & 31 & 25,83 & & 35 & 29,17 & \\
\hline
\end{tabular}

\subsection{Ensaios de adsorção e dessorção com misturas binárias em leito fixo}

A Figura 4 ( $\mathrm{a}$ e b) mostram os cromatogramas obtidos para a mistura binária de ácido lático (345 g/L) e glicerina com a resina Amberlite IRA 67 e a Amberlite IRA 96, respectivamente.

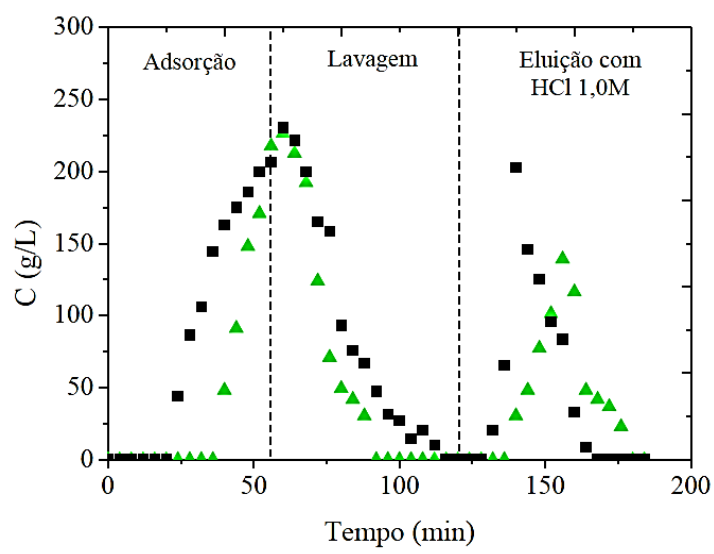

(a)

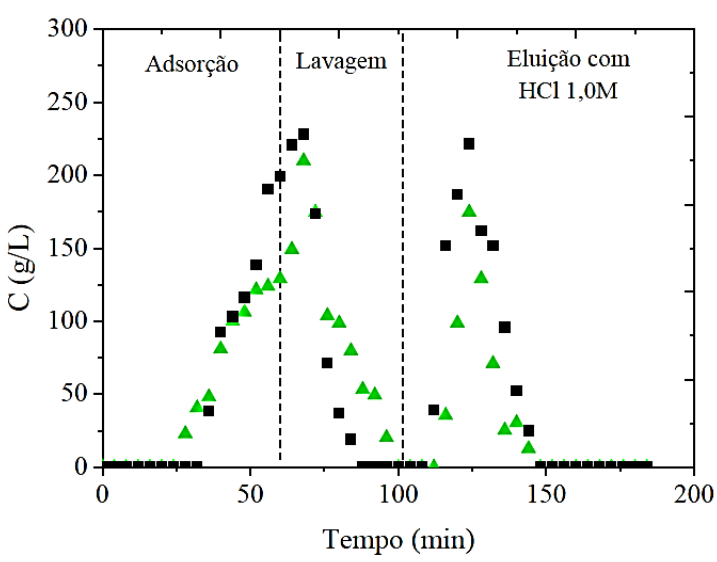

(b)

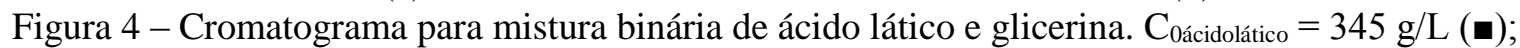
$\mathrm{C}_{0 \mathrm{Glicerina}}=230 \mathrm{~g} / \mathrm{L}(\Delta) ; \mathrm{T}=30^{\circ} \mathrm{C} ; \mathrm{Q}=2,5 \mathrm{~mL} / \mathrm{min}$, na resina Amberlite IRA 67 (a) e Amberlite IRA 96 (b).

Pode se observar que na tabela 4, que o percentual de recuperação do ácido lático comercial da solução na etapa de eluição, foi de 22,61\% (78 g/L) para a resina Amberlite IRA 67 e 31,30\% (108 g/L) para a resina Amberlite IRA 96. É importante ressaltar que foi feito o acompanhamento da recuperação de glicerina do meio para saber o quanto isso pode afetar a adsorção do componente de interesse (ácido lático), sendo observado que o percentual de recuperação de glicerina na etapa de eluição permaneceu na faixa de 24-28\%. Foram obtidos valores de produtividade de 7,00 e $9,71 \mathrm{Kg}$ de ácido lático $/ \mathrm{kg}$ de resina.dia para a resina Amberlite IRA 67 e IRA 96, respectivamente. 
Tabela 4 - Etapas da corrida cromatográfica da mistura binária (ácido lático + glicerol) nas resinas Amberlite IRA 67 e IRA 96

\begin{tabular}{|c|c|c|c|c|c|}
\hline \multicolumn{6}{|c|}{ Amberlite IRA 67} \\
\hline \multirow[b]{2}{*}{ Etapa } & \multicolumn{3}{|c|}{ Ácido Lático } & \multicolumn{2}{|c|}{ Glicerol } \\
\hline & $\begin{array}{l}\text { Conc. } \\
\text { (g/L) }\end{array}$ & $\begin{array}{c}\text { Percentual } \\
\text { da conc. }(\%)\end{array}$ & $\begin{array}{c}\text { PR } \\
\text { (kg/ (kg. dia) }\end{array}$ & $\begin{array}{l}\text { Conc. } \\
\text { (g/L) }\end{array}$ & $\begin{array}{l}\text { Percentual da } \\
\text { conc. }(\%)\end{array}$ \\
\hline Alimentação & 345 & 100 & \multirow{4}{*}{7,00} & 230 & 100 \\
\hline Adsorção & 154 & 44,63 & & 131 & 56,96 \\
\hline Lavagem & 113 & 32,75 & & 32 & 13,91 \\
\hline Eluição & 78 & 22,61 & & 66 & 28,69 \\
\hline \multicolumn{6}{|c|}{ Amberlite IRA 96 } \\
\hline & \multicolumn{3}{|c|}{ Ácido Lático } & \multicolumn{2}{|c|}{ Glicerol } \\
\hline Etapa & $\begin{array}{l}\text { Conc. } \\
\text { (g/L) }\end{array}$ & $\begin{array}{c}\text { Percentual } \\
\text { da conc. }(\%)\end{array}$ & $\begin{array}{c}\text { PR } \\
\text { (kg/ (kg. dia) }\end{array}$ & $\begin{array}{l}\text { Conc. } \\
\text { (g/L) }\end{array}$ & $\begin{array}{l}\text { Percentual da } \\
\text { conc. }(\%)\end{array}$ \\
\hline Alimentação & 345 & 100 & \multirow{4}{*}{9,71} & 230 & 100 \\
\hline Adsorção & 162 & 46,95 & & 113 & 49,13 \\
\hline Lavagem & 75 & 21,74 & & 59 & 25,65 \\
\hline Eluição & 108 & 31,30 & & 57 & 24,78 \\
\hline
\end{tabular}

\subsection{Ensaios de adsorção e dessorção com mistura real em leito fixo}

A Figura 5 (a e b) mostram os cromatogramas obtidos para a mistura real com a resina Amberlite IRA 67 e a Amberlite IRA 96, respectivamente.

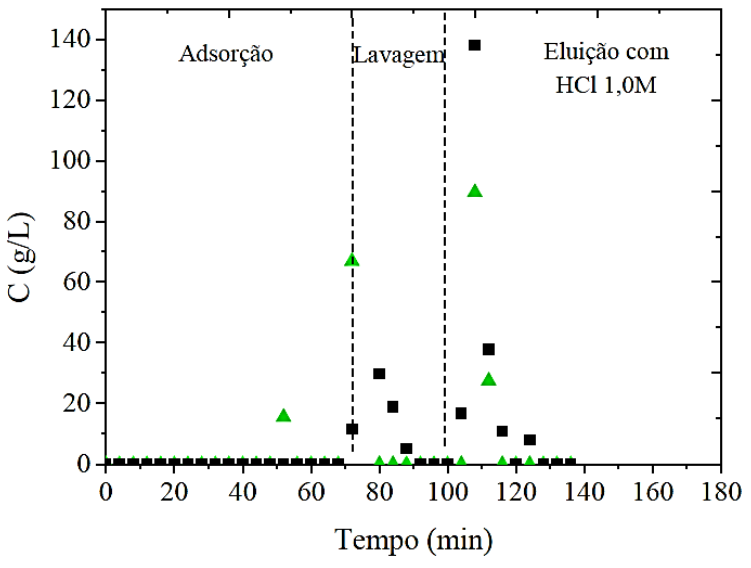

(a)

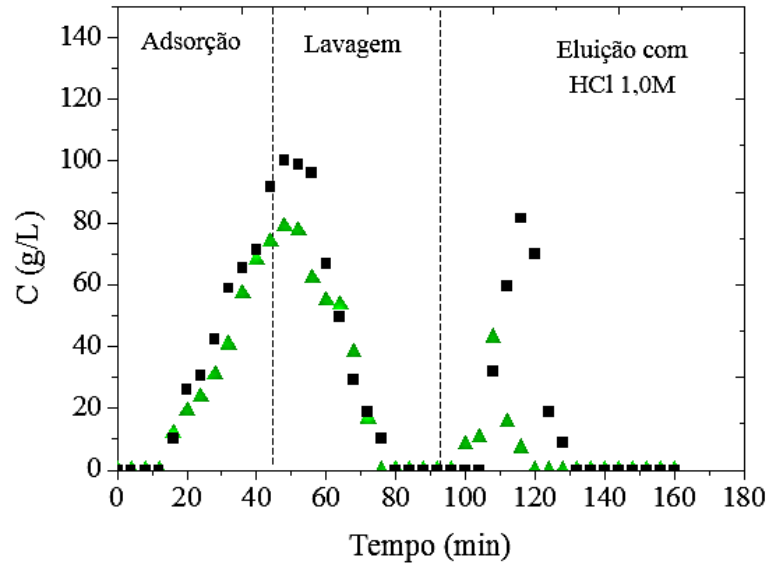

(b)

Figura 5 - Cromatograma para mistura real. $\mathrm{C}_{\text {0ácidolático }}=138 \mathrm{~g} / \mathrm{L}(\mathbf{\bullet}) ; \mathrm{C}_{\text {OGlicerina }}=34 \mathrm{~g} / \mathrm{L}(\Delta)$ para a resina Amberlite IRA 67 (a) e $\mathrm{C}_{\text {ácidolático }}=115 \mathrm{~g} / \mathrm{L}(\mathbf{\bullet}) ; \mathrm{C}_{0 \mathrm{Glicerina}}=80 \mathrm{~g} / \mathrm{L}(\Delta)$ para a resina Amberlite IRA 96 (b), nas condições $\mathrm{T}=30^{\circ} \mathrm{C} ; \mathrm{Q}=2,5 \mathrm{~mL} / \mathrm{min}$.

É importante lembrar que pode ter havido eventuais perdas (mínimas) de amostras durante o processo. $\mathrm{O}$ valor de produtividade ( $\mathrm{kg}$ de ácido lático $/ \mathrm{kg}$ de resina.dia) obtido para a amostra real foi de 1,97 para a resina Amberlite IRA 67 e de 2,43 para a resina Amberlite IRA 96, apresentando esta última um melhor desempenho na adsorção de ácido lático. 
Tabela 5 - Etapas da corrida cromatográfica da mistura real nas resinas Amberlite IRA 67 e IRA 96

\begin{tabular}{|c|c|c|c|c|c|}
\hline \multicolumn{6}{|c|}{ Amberlite IRA 67} \\
\hline \multirow[b]{2}{*}{ Etapa } & \multicolumn{3}{|c|}{ Ácido Lático } & \multicolumn{2}{|c|}{ Glicerol } \\
\hline & $\begin{array}{l}\text { Conc. } \\
\text { (g/L) }\end{array}$ & $\begin{array}{c}\text { Percentual } \\
\text { da conc. }(\%)\end{array}$ & $\begin{array}{c}\text { PR } \\
\text { (kg/ (kg. dia) }\end{array}$ & $\begin{array}{l}\text { Conc. } \\
(\mathrm{g} / \mathrm{L})\end{array}$ & $\begin{array}{l}\text { Percentual da } \\
\text { conc. }(\%)\end{array}$ \\
\hline Alimentação & 138 & 100 & \multirow{4}{*}{1,97} & 34 & 100 \\
\hline Adsorção & 68 & 49,28 & & 17,55 & 51,62 \\
\hline Lavagem & 41 & 29,71 & & 9,43 & 27,73 \\
\hline Eluição & 22 & 15,94 & & 6,56 & 19,29 \\
\hline \multicolumn{6}{|c|}{ Amberlite IRA 96} \\
\hline \multirow[b]{2}{*}{ Etapa } & & Ácido Látic & & & \\
\hline & $\begin{array}{l}\text { Conc. } \\
(\mathrm{g} / \mathrm{L})\end{array}$ & $\begin{array}{c}\text { Percentual } \\
\text { da conc. }(\%)\end{array}$ & $\begin{array}{c}\text { PR } \\
\text { (kg/ (kg. dia) }\end{array}$ & $\begin{array}{l}\text { Conc. } \\
(\mathrm{g} / \mathrm{L})\end{array}$ & $\begin{array}{l}\text { Percentual da } \\
\text { conc. }(\%)\end{array}$ \\
\hline Alimentação & 115 & 100 & \multirow{4}{*}{2,43} & 80 & 100 \\
\hline Adsorção & 50 & 43,48 & & 40 & 50,00 \\
\hline Lavagem & 37 & 32,17 & & 30 & 37,5 \\
\hline Eluição & 27 & 23,48 & & 8 & 10,00 \\
\hline
\end{tabular}

\section{CONCLUSÕES}

Os resultados apresentados neste estudo mostraram que as resinas de troca iônica utilizadas para o processo de purificação do ácido lático em coluna de leito fixo apresentaram uma grande capacidade de adsorção do ácido em solução monocomponente, binária e em mistura real.

\section{REFERÊNCIAS}

ABDEL-RAHMAN, M. A.; TASHIRO, Y.; SONOMOTO, K. Lactic acid production from lignocellulose-derived sugars using lactic acid bacteria: Overview and limits. J. Biotechnol., 156, 286-301, 2011.

DEY, P.; PAL, P. Direct production of $1(+)$ lactic acid in a continuous and fully membraneintegrated hybrid reactor system under non-neutralizing conditions. J. Membrane Sci., 389, 355-362, 2012.

HOFVENDAHL, K.; HAHN-HAGERDAL, B. Factors affecting the fermentative lactic acid production from renewable resources. Enzyme Microb. Tech., v. 26, p. 87-107, 2000.

LOPES, A. N.; CECHINEL, C. A.; WENTZ, A. P. Co-produto do biodiesel - novas aplicações para glicerina. Diálogos \& Ciência - Revista da Faculdade de Tecnologia e Ciências - Ano 9, n. 27, set. 2011.

SHEN, Z.; JIN, F.; ZHANG, Y.; WU, B.; KISHITA, A.; TOHJI, K.; KISHIDA, H. Effect of alkaline catalysts on hydrothermal conversion of glycerin into lactic acid. Ind. Eng. Chem. Res., v. 48, p. 8920-8925, 2009.

SILVA, A. H. Estudos de adsorção de ácidos orgânicos visando sua recuperação de meios fermentados. 2010.134 f. Dissertação (Mestrado em Engenharia Química) - Departamento de Engenharia Química, Universidade Estadual de Campinas, São Paulo, 2010.

UMPIERRE, A. P.; MACHADO, F. Gliceroquímica e Valorização do Glicerol. Revista Virtual de Química, v. 5, p. 106-116, 2013.WASEWAR, K. L. Separation of Lactic Acid: Recent Advances. Chem. Biochem. Eng. v.19, p. 159-172, 2005. 